\title{
Üç Boyutlu T1 Ağırlıklı Manyetik Rezonans Görüntülerinde Ön İşleme Yöntemleri
}

\author{
Muhammet Üsame Öziç ${ }^{1 *}$, Seral Özşen² \\ ${ }^{1}$ Necmettin Erbakan Üniversitesi, Biyomedikal Mühendisliği, Konya, Türkiye (ORCID: 0000-0002-3037-2687) \\ ${ }^{2}$ Konya Teknik Üniversitesi, Elektrik-Elektronik Mühendisliği, Konya, Türkiye (ORCID: 0000-0001-5332-8665)
}

(İlk Geliş Tarihi 13 Nisan 2020 ve Kabul Tarihi 23 Mayıs 2020)

(DOI: 10.31590/ejosat.719062)

ATIF/REFERENCE: Öziç, M. Ü. \& Özşen, S. (2020). Üç Boyutlu T1 Ağırlıklı Manyetik Rezonans Görüntülerinde Ön İşleme Yöntemleri. Avrupa Bilim ve Teknoloji Dergisi, (19), 227-240.

$\ddot{O} \mathbf{z}$

T1 ağırlıklı üç boyutlu yapısal manyetik rezonans görüntüleme, hastalıklardan dolayı beyinde meydana gelen doku bozuklukları ve hacimsel kayıpların yüksek çözünürlükte görüntülenmesini sağlayan bir görüntüleme tekniğidir. Bu görüntüleme tekniği ile hastaya dışarıdan herhangi bir müdahale yapılmadan görüntüler alınabilmektedir. Fiziksel olarak görüntü alımının temelinde radyo frekans teknolojisi bulunmaktadır. Öncelikle beyinde bulunan hidrojen atomlarındaki protonların etkileşime gireceği bir radyo frekans dalga gönderilir. Radyo frekans dalgası durdurulduğunda protonlar eski durumlarına geri dönmek eğilimindedir. Eski durumlarına dönerken, yaydıkları enerji bir akım olarak toplanır ve indüklenir, daha sonra görüntü Fourier dönüşümleri ile elde edilir. Görüntüler isteğe göre farklı sekanslarda alınabilir. Her bir sekansın hastalı̆ga göre klinikte farklı ayırt edici özellikleri bulunmaktadır. Manyetik rezonans görüntüleri birbirini takip eden kesitlerden oluşur. Hastalık herhangi bir kesitte gözlemlenebileceği gibi birbirini takip eden birkaç kesitin beraber analiz edilmesi ile de görülebilmektedir. Manyetik rezonans görüntü sekansları içerisinde en çok kullanılan görüntüler üç boyutlu T1 ağırlıklı görüntülerdedir. Bu sekansta yumuşak beyin dokusu yüksek çözünürlükte görüntülenebildiği için hacimsel bozukluklar, dejenerasyon, simetri bozulması, doku bozulması, beyin küçülmesi ve büyümesi gibi birçok katı değiş̧iklikler net bir şekilde izlenebilmektedir. Elde edilen görüntüler hastanelerde radyologlar tarafindan analiz edilerek yorumlanmaktadır. Ancak özellikle yapay zeka ve sınıflandırma çalışmalarında birtakım sayısal araçlara ihtiyaç duyulmaktadır. Bu sayısal araçların kullanılabilmesi için görüntüler üzerinde bazı ön işlemelerin yapılması gerekmektedir. Bu çalışmada T1 ağırlıklı üç boyutlu yapısal manyetik rezonans görüntülerinin ön işleme yöntemlerinden olan eksen dönüştürme, görüntü reoryantasyonu, normalizasyon, modülasyon, segmentasyon, birlikte çakıştırma, gürültü ve bias giderme, yumuşatma, beyin dışı yapıların giderilmesi incelenmiştir. Ön işleme için kullanılan sayısal araçların nasıl ve hangi sırada kullanılacağı tanımlanmış ve üç boyutlu bir manyetik rezonans görüntü üzerinde uygulamaları yapılmıştır.

Anahtar Kelimeler: Manyetik Rezonans, Ön işleme, 3B Analiz, T1 MR, Radyoloji.

\section{Pre-processing Methods on Three Dimensional T1 Weighted Structural Magnetic Resonance Images}

\begin{abstract}
T1 weighted three-dimensional structural magnetic resonance imaging is an imaging technique that enables high resolution imaging of tissue defects and volumetric losses in the brain due to diseases. With this imaging technique, images can be taken without any external intervention to the patient . Radio frequency technology is at the basis of physical image acquisition. Firstly, a radio frequency wave is sent in which the protons in the hydrogen atoms in the brain will interact. When the radio frequency wave is stopped, protons tend to return to their former state. While returning to their former state, the energy their emitted is collected and
\end{abstract}

\footnotetext{
* Sorumlu Yazar: Necmettin Erbakan Üniversitesi, Mühendislik ve Mimarlık Fakültesi, Biyomedikal Mühendisliği Bölümü, Konya, Türkiye, ORCID: 0000-0002-3037-2687, muozic@gmail.com
} 
induced as a current, then the image is obtained by Fourier transforms. Images can be taken in different sequences upon request. Each sequence has different distinctive features in the clinic with respect to the disease. Magnetic resonance images consist of successive slices. The disease can be observed in any slice, or it can be seen by analyzing several slices in succession. Among the magnetic resonance image sequences, the most used images are in 3D T1-weighted images. Since soft brain tissue can be displayed in high resolution in this sequence, many rigid changes such as volumetric disorders, degeneration, symmetry disruption, tissue disruption, brain shrinkage and enlargement can be clearly observed. The images obtained are analyzed and interpreted by radiologists in hospitals. However, some numerical tools are needed especially in artificial intelligence and classification studies. In order to use these numerical tools, some preprocessing must be done on the images. In this study, axis conversion, image reorientation, normalization, modulation, segmentation, co-registration, noise and bias removal, smoothing, removal of non-brain structures are examined, which are the preprocessing methods of T1-weighted three-dimensional structural magnetic resonance images. How and in which order to use the numerical tools used for pre-processing has been defined and their applications are made on a threedimensional magnetic resonance image.

Keywords: Magnetic Resonance, Pre-processing, 3D Analysis, T1 MR, Radiology.

\section{Giriş}

Medikal görüntüler kullanılarak görüntü işleme ve makine öğrenmesi gibi sayısal yöntemler ile hastalıkların analizi ve sınıflandırılması literatürde sıklıkla çalışılan bir konudur (Gülay \& İçer, 2020; Özel, 2020; Varol \& İşeri, 2019). Bu görüntüler ile bilgisayar destekli karar destek sistemleri tasarlanabilmekte, hastalıklar hakkında tahminler yapılabilmektedir. Medikal görüntüler içerisinde T1 ağırlıklı yapısal Üç Boyutlu (3B) Manyetik Rezonans (MR) görüntüleri, klinikte ve bilgisayar destekli karar destek sistemleri tasarlamak için sıklıkla kullanılmaktadır. Bu görüntüleme tekniği beyindeki yumuşak dokuları yüksek çözünürlükte gösterebildiği için nörolojik hastalıkların takibinde sıklıkla kullanılan bir tekniktir. Görüntüler üzerinde atrofi farklılığı, hacim kaybı veya artışı, dejenerasyon, simetri bozulması, doku bozulması, lezyon takibi ve analizi yapılabilmektedir. Hastanelerde çekilen görüntülerin analizi alanında tecrübeli radyologlar tarafından yapılmaktadır. Bu analizler, ilgili klinikteki doktorun teşhis koyması için yeterlidir. Ancak görüntülerin bilgisayar ortamında sayısal olarak işlenmesi, hacim, patoloji takibi, atrofi farklılıkları, segmentasyon, çakıştırma, hasta ve kontrol grupları arasındaki farklılıkların belirlenmesi, karar destek sistemlerinin tasarlanması gibi işlemlerin yapılabilmesi için öncesinde birtakım zorluklar bulunmaktadır. Cihaz manyetik alanından kaynaklanan ve diğer çevresel faktörlerden ortaya çıkan rastgele gürültüler, kemik ve zar dokusu gibi beyin dışı yapılar, hastanın cihaz içindeki kafa hareketinden kaynaklı görüntü kaymaları, her hastanın kafa boyutunun farklı olması, çekilen görüntüler arasındaki boyut farklılıkları bilgisayar destekli sayısal analizleri son derece zorlaştırmaktadır. Dolayısıyla sayısal analiz için birtakım ön işlemelerin yapılması gerekmektedir (Hemanth \& Anitha, 2012; Patil \& Udupi, 2012). Ön işleme için çözüm önerileri literatürde sıklıkla çalışılan bir konudur. MR görüntülerinin sayısal analizi için son güncel algoritmaların içinde bulunduğu paket programlar literatürde sıklıkla kullanılmaktadır. College London Üniversitesi tarafından geliştirilen MATLAB tabanlı Statistical Programming Mapping 8 (SPM) (UCL, 2020), Harvard Üniversitesi tarafından geliştirilen Linux tabanlı Freesurfer (Fischl, 2012), Oxford üniversitesi tarafından geliştirilen Linux tabanlı FSL (Jenkinson, Beckmann, Behrens, Woolrich, \& Smith, 2012) literatürde kullanılan en popüler paket programlardır. Bu çalışmada, yapısal MR görüntülerinin 3B uzayda analiz öncesi yapılması gereken ön işleme yöntemlerinin bir uygulaması yapılmıştır. Ön işleme için MRIcro programı (Rorden, 2005), SPM8 programı ve bu programın altında çalışan VBM8 (F Kurth, Luders, \& Gaser, 2010) kütüphanesi kullanılmıştır. Çalışmada uluslararası bir veri tabanı olan The Open Access Series of Imaging Studies (OASIS) veri tabanından alınan Klinik Demans Derecelendirmesi 1 (KDR1) alzheimer hastası kadın denek MR görüntüsü üzerinden denemeler yapılmıştır (Marcus et al., 2007). Denek görüntüsü üzerinden eksen dönüştürme, görüntü reoryantasyonu, gürültü ve bias giderme, beyin dışı yapıların atılması, segmentasyon, yumuşatma, normalizasyon, modülasyon, birlikte çakıştırma olmak üzere dokuz ön işleme yöntemi incelenmiş ve uygulamaları yapılmıştır.

\section{Materyal ve Metot}

\subsection{Veri}

Bu çalışmada, ön işleme yöntemlerinin uygulamaları için OASIS veri tabanından alınan KDR1 alzheimer hastası bir kadın denek T1 ağırlıklı 3B MR görüntüsü kullanılmıştır (Marcus et al., 2007). 3B MR görüntüsü, ön işlemeye tabi tutulmamış “OAS1_0028_MR1_mpr_n4_anon_sbj_111” önekli, 256x256 görüntü ve 1x1x1 voksel boyutlu olup 160 kesitten oluşmaktadır. Bu görüntünün çekim protokolleri $\mathrm{TE}=4.0 \mathrm{msn}, \mathrm{TR}=9.7 \mathrm{msn}, \mathrm{TI}=20 \mathrm{msn}, \mathrm{TD}=200 \mathrm{msn}, \mathrm{FA}=10$ olmak üzere Siemens (Erlangen, Germany) marka 1.5T cihaz ile alınan Magnetization Prepared Rapid Gradient Echo (MPRAGE) uzantılı volümetrik ve NIfTI dosya formatı şeklindedir (Marcus et al., 2007). NIfTI dosya formatı şeklindeki görüntüler *.nii veya *.img uzantılı olup MRIcro ve SPM programları üzerinden görüntülenebilmektedir. Şekil 2.1'de OAS1_0028 nolu deneğin MR görüntüsünün sagital eksende tek kesit ve üç eksen gösterimi verilmiştir. 

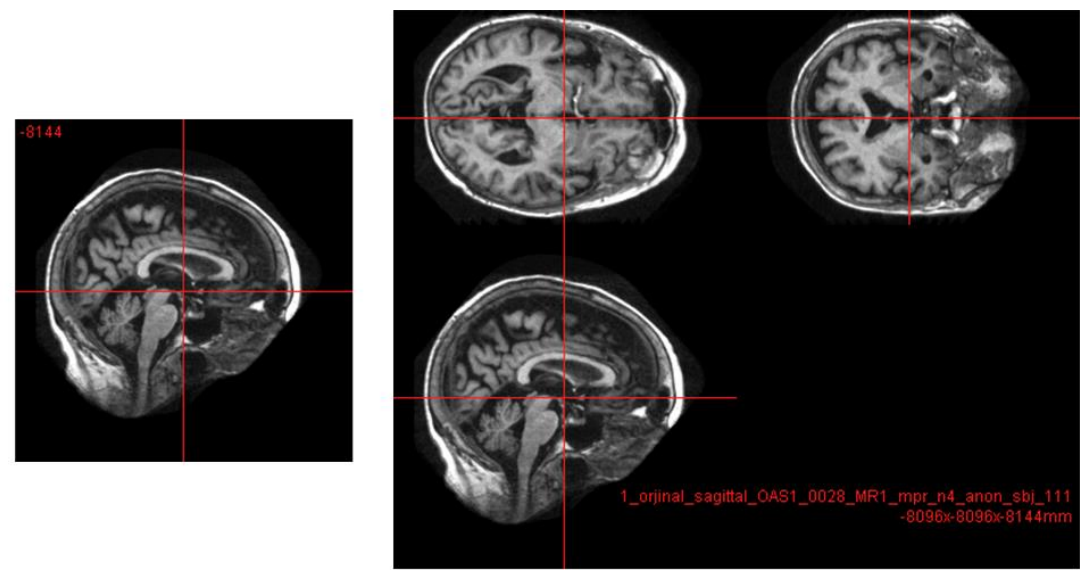

Şekil 2.1. OAS1_0028 görüntüsünün sagital eksende tek kesit ve üç eksen gösterimi

\subsection{MRIcro, SPM8 Programı ve VBM8 Kütüphanesi}

SPM8 programı College London Üniversitesi Nöroloji Enstitüsü tarafından geliştirilen farklı sinyal ve görüntülerin ön işleme ve analizine imkân sağlayan MATLAB tabanlı bir programdır. Bu program ile yapısal MR, fonksiyonel MR, PET görüntüleri ile EEG/MEG sinyallerinin ön işlemeleri ve analizleri yapılabilmektedir. Her bir ön işleme ve analiz araçları güncel versiyonları ile son kullanıcıya hizmet vermektedir. SPM8 programı açık kaynak olup kullanıcılar program altyapısını kullanarak kendilerine ait kütüphaneler oluşturabilmektedirler. Bu kütüphaneler SPM web sitesinden dünyadaki araştırmacıların kullanımına sunulabilmektedir. VBM8 kütüphanesi SPM8 programının altyapısını kullanarak yapısal MR için özelleştirilmiş araçları barındırmaktadır (F Kurth et al., 2010). Kullanıcı eksen dönüştürme ve reoryantasyon işlemlerini yaptıktan sonra ham MR görüntüsünü girilen parametre değerlerine göre istenilen ön işlemeler yapılmış olarak elde edebilmektedir. VBM8 kütüphanesi indirildikten sonra SPM8 programının "toolbox" klasörü içerisine eklenmelidir. Kütüphane eklenmiş SPM8 aracının MATLAB programında “Addpath” seçeneği kullanılarak yolu tanımlanmalıdır. Böylece MATLAB komut ekranına "spm” yazılarak Şekil 2.2a'da verilen program arayüzüne ulaşılabilir. fMRI sekmesi ile girilen arayüzde "toolbox” seçeneğine tıklandığında listedeki "vbm8” komutu ile kütüphane aracına kolaylıkla ulaşılabilir. Şekil 2.2b ve Şekil 2.2c'de fMRI arayüzü ve VBM8 program başlangıcı gösterilmektedir. Bazı ön işleme ve basit araçları ile MRIcro beyin analizlerinde kullanışlı bir programdır (Rorden, 2005). Çalışmada MRIcro programı sadece eksen dönüştürme işlemi için kullanılmıştır. Şekil 2.2d'de MRIcro arayüzü gösterilmektedir.

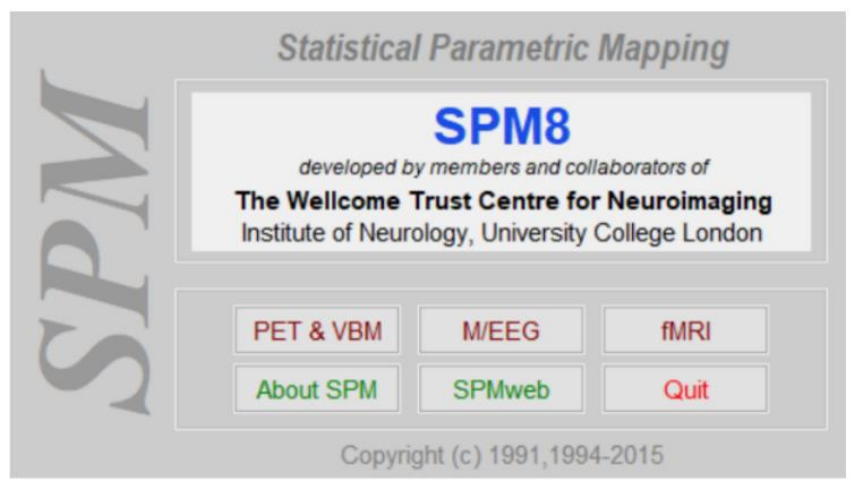

(a)

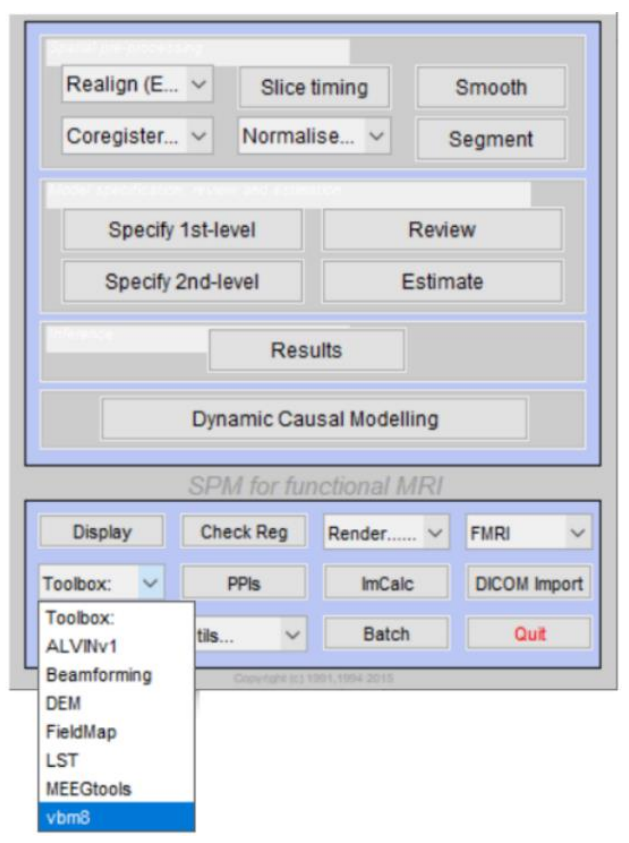

(b) 


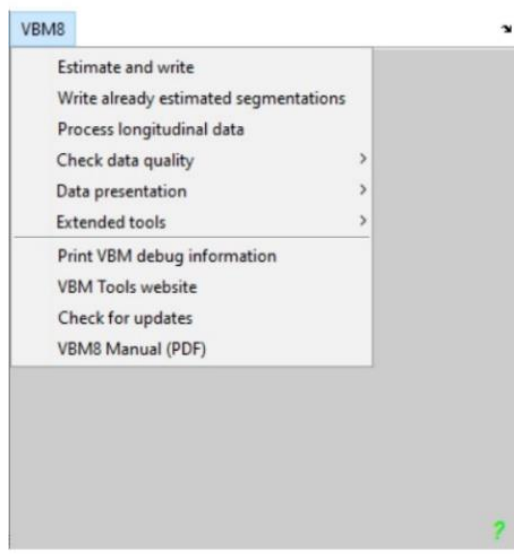

(c)

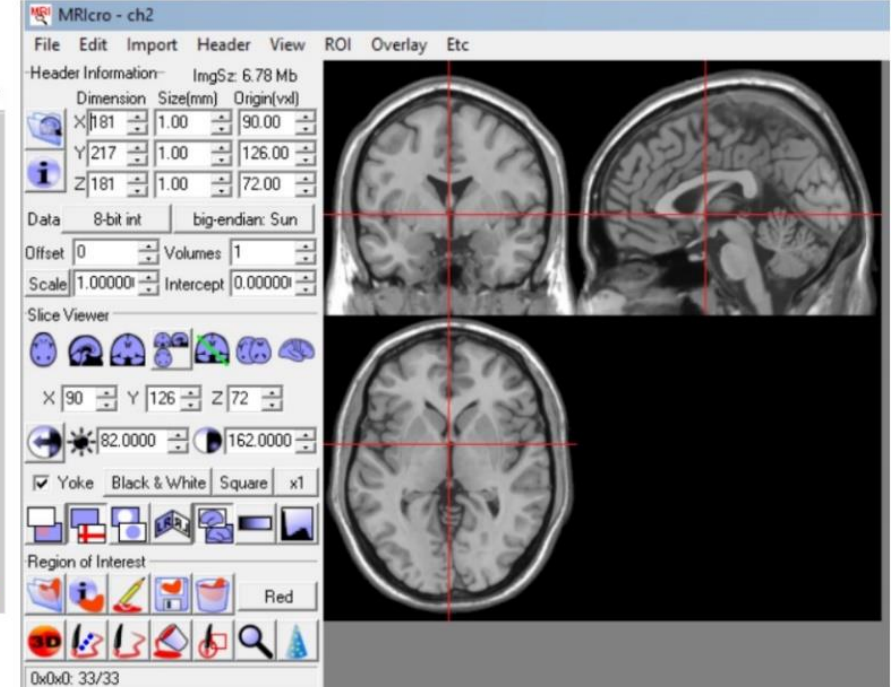

(d)

Şekil 2.2. (a) SPM8 arayüzü (b) fMRI arayüzü (c) VBM8 arayüzü (d) MRIcro arayüzü (Öziç, 2018)

\subsection{Eksen Dönüștürme}

3B MR görüntüleri aksiyal, sagital veya koronal eksenlerin herhangi birinden alınabilmektedir. SPM8 programı içerisindeki birçok şablon aksiyal eksende tanımlandığı için görüntülerin aksiyal eksene dönüştürülmesi gerekmektedir (Ashburner et al., 2008). Görüntülerin "header" dosyalarında, hangi vokselin hangi koordinatlarda tutulduğunun bilgisi bulunmaktadır. MRIcro programı bu bilgiyi kullanarak görüntülerin çekildiği eksenden aksiyal eksene dönüştürülmesi için bir araç bünyesinde barındırmaktadır. Program görüntüleri istenilen eksende tekrar dilimlemektedir. OASIS veri tabanından alınan 3B MR görüntüsü sagital eksende alındığı için aksiyal eksene dönüştürülmesi gerekmektedir. Bu işlem sonucunda görüntünün içeriğinde herhangi bir değişiklik olmamakta, sadece görüntüye bakılan yön değiştirilmektedir. Bundan dolayı aksiyal eksende 160 kesit yerine 256 kesit oluşmakta, görüntü boyutu 256x256 yerine 160x256 görüntü boyutuna dönüşmektedir. Voksel boyutlarında herhangi bir değişiklik olmamaktadır. Şekil 2.3’te sagital eksende alınmış görüntünün aksiyal eksene dönüştürülmüş şekli verilmiştir.
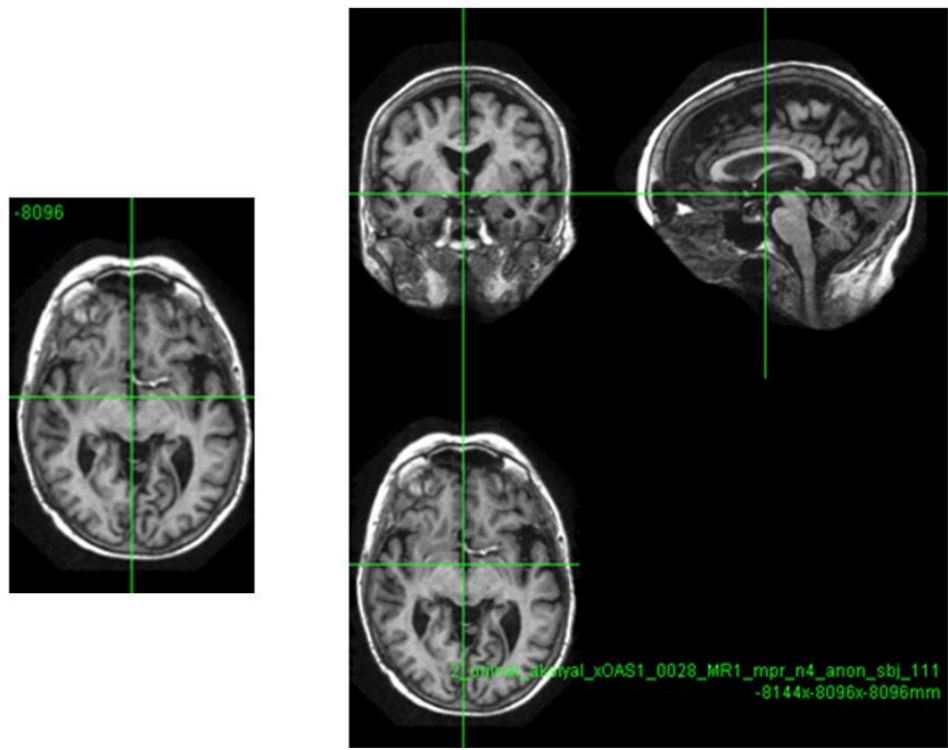

Şekil 2.3. OAS1_0028 görüntüsünün sagital eksenden aksiyal eksene dönüştürülmüş tek kesit ve üç eksende gösterimi 


\subsection{Görüntü Reoryantasyonu}

Görüntü reoryantasyonu, beyin görüntüsünün 3B uzayda bir noktadan diğer bir noktaya kaydırılması işlemidir. Bu işlem sırasında voksellerin bulundukları koordinatlarda döndürme (rotation) ve öteleme (translation) olmak üzere iki hareket yapılır. SPM8 programı üzerinde açılan bir panel kullanılarak x, y, z ve yaw, pitch, roll açıları ile altı farklı açısal kaydırma yapılabilmektedir. Tek bir yönde açısal hareket yapılabileceği gibi altı farklı giriş ile üç boyutlu hareket yaptırılabilmektedir. İşlem sırasında voksel komşuluk intensiteleri değişmemekte olup sadece katı dönüşüm gerçekleştirilmektedir (Davis \& Loh, 2011). Bu işlem cihazda görüntü eldesi sırasında hastanın kafa hareketlerinden ve beynin merkez koordinatlarının kaymasından dolayı gerekli bir ön işlemdir. 3B MR görüntülerinin merkezi x,y,z=0 Anterior Commissure (AC) noktası olarak kabul edilmektedir (Talairach \& Tournoux, 1988). Anterior Commisure ve Posterior Commissure (PC) noktalarından geçen çizgi merkez orijin çizgisi, bu çizgiden çekilen düzlem ise beynin orta düzlemi (midsagittal plane) olarak tanımlanmıştır (Liu, Collins, \& Rothfus, 2001). SPM8 programında kullanılan şablonlar AC noktasını merkez olarak belirlediği için görüntünün bu nokta kullanılarak tekrar reoryantasyon yapılması gerekmektedir. Aksi halde şablon ile görüntü tam oturmadığı için VBM8 kütüphanesi hata vermekte veya elde edilen segmentasyon görüntülerinde yer yer deformasyonlar görülebilmektedir (Florian Kurth, Gaser, \& Luders, 2015). AC noktası her ne kadar tam olarak oturtulamazsa da olabildiğince yakın olmasının yeterli olacağı belirtilmiştir (Ridgway, 2010b). Şekil 2.4a'da sagital eksende mavi imlecin ortasında, corpus callosum altında bulunan nokta AC noktasıdır. Ancak panel altında bulunan kırmızı dikdörtgen içerisinde bulunan koordinat değerlerinin [8143.5 8087.5 8089.6] olduğu görülmektedir. Bu değerlerin Şekil 2.4b’de verildiği gibi [0 0 0] noktasına çekilmesi için alt panelde bulunan $\mathrm{x}, \mathrm{y}, \mathrm{z}$ değerlerine bu koordinat değerlerinin zıt yönleri girilerek reoryantasyon işlemi ile düzeltme yapılmıştır. Şekil 2.4c'de görüntünün reoryantasyon yapılmış şekli, Şekil 2.4d'de reoryantasyon işlemi yapılmazsa MATLAB'ın verdiği hata gösterilmektedir.
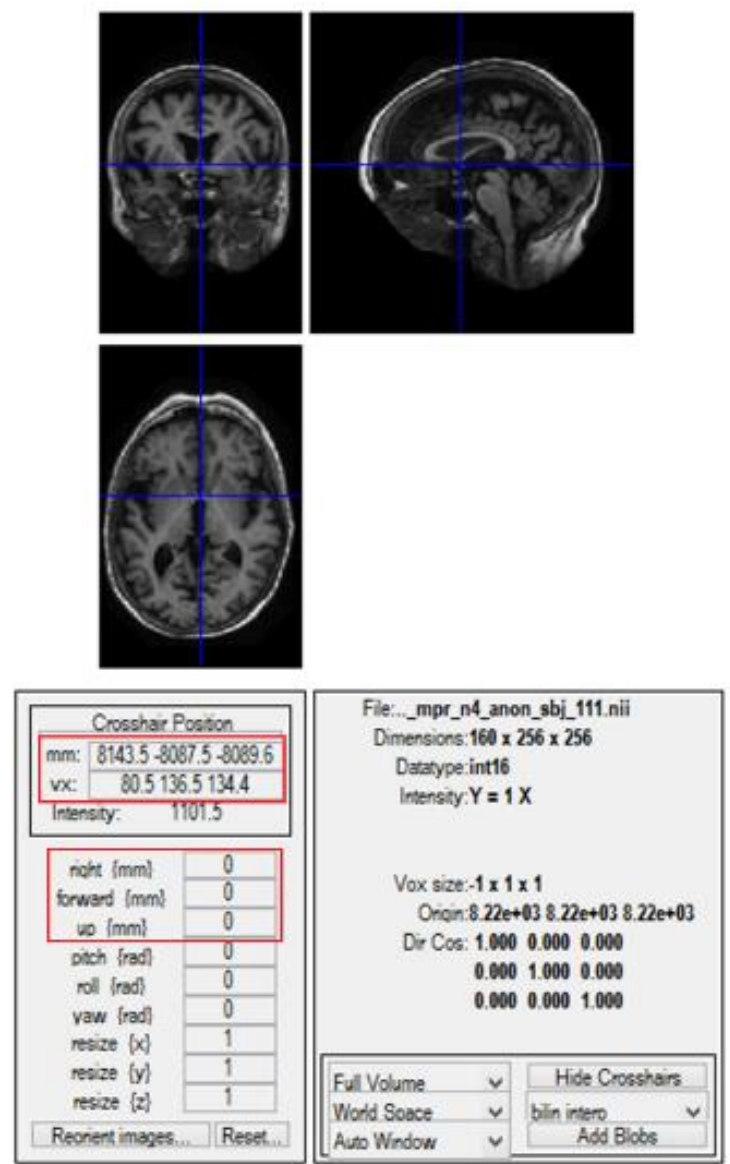

(a)
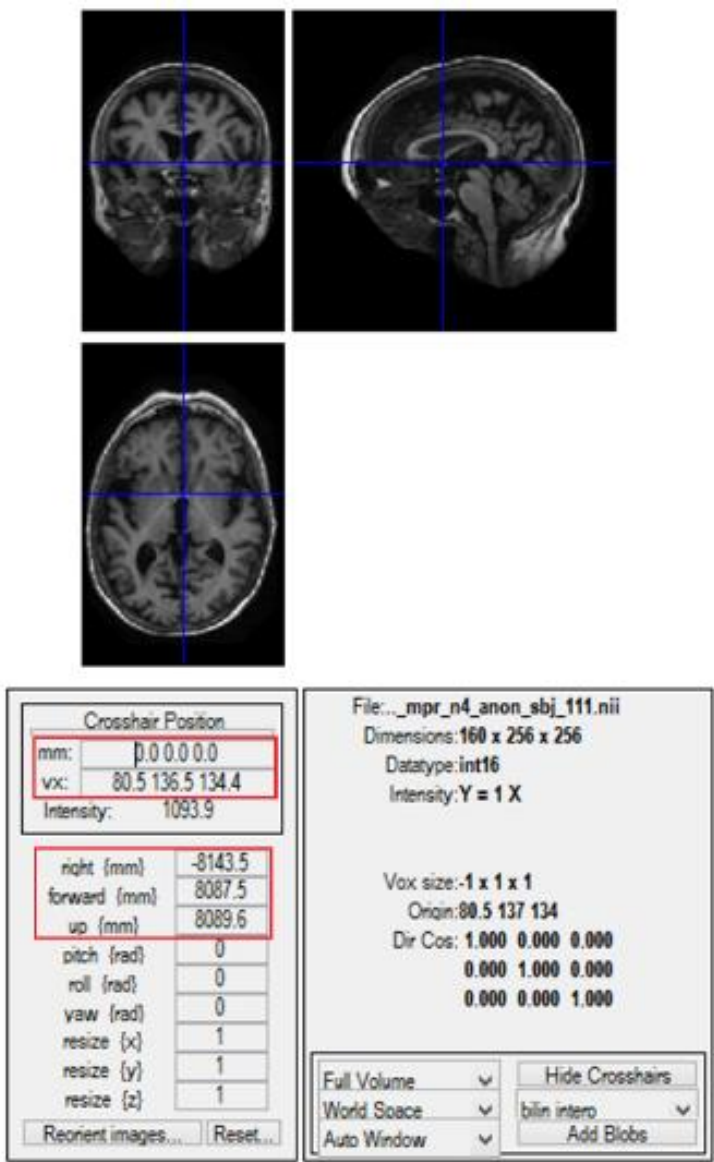

(b) 


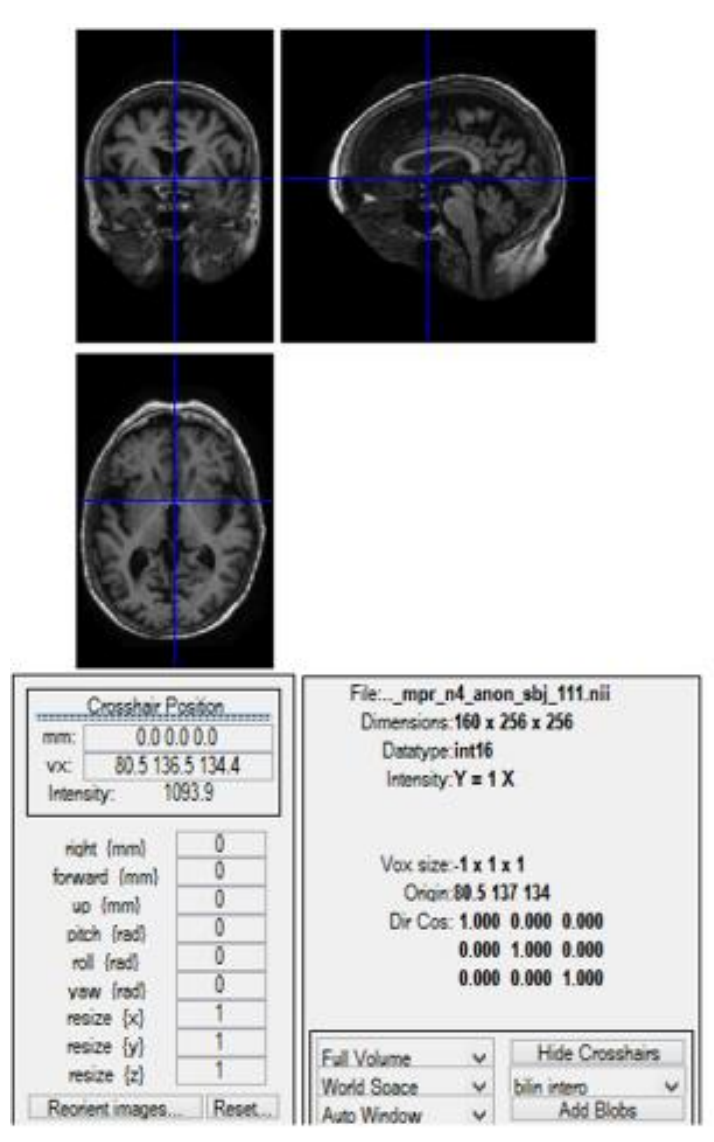

(c)

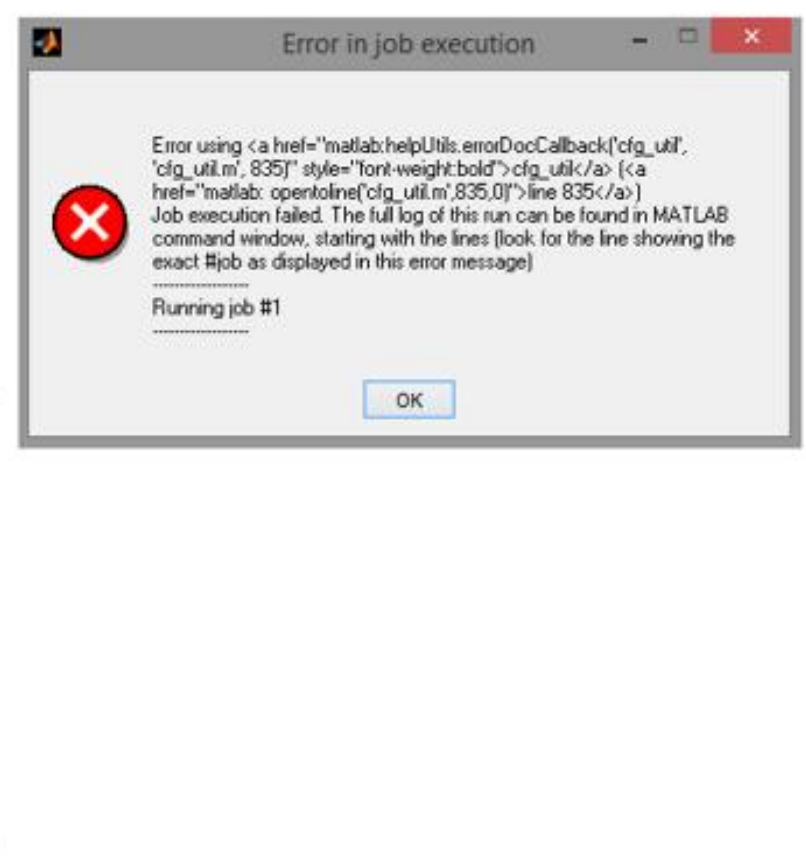

(b)

Şekil 2.4. (a) Ham görüntü ve koordinatları (kırmızı kutu içerisinde) (b) Düzeltme için girilen koordinatlar (c) Görüntünün $x, y, z=0$ olarak ayarlanmış durumu (d) İlgili koordinat değişimi yapılmadığında MATLAB'ın vermiş olduğu hata görüntüsü (Öziç, 2018)

\subsection{Gürültü ve Bias Giderme}

MR görüntüleri cihazdan alınırken elektromanyetik dalgalardan ve çevreden gelen rastgele gürültülerden etkilenmektedir. Bu etkiden kaynaklı olarak görüntü üzerinde istenmeyen vokseller meydana gelir. İstenmeyen voksel değerleri analiz sırasında görüntülerde bozulmalar oluşturmaktadır. Gürültüler rastgele oluştuğu için klasik gürültü giderme algoritmaları ile güçlü sonuçlar alınamamaktadır. Kullanılan gürültü giderme algoritmalarının anlamlı vokselleri yok etmeden adaptif bir şekilde gürültüyü yok etmesi gerekmektedir. Genel olarak MR görüntülerinde bias ve diğer gürültüler olmak üzere iki gürültü çeşidi tanımlanmaktadır. Bias gürültüsü çekim esnasında kullanılan radyo frekans dalgalardan kaynaklı bir gölge gürültüsü oluşturur. Bu gürültü tipine literatürde hayalet (ghost) gürültü de denilmektedir. Diğer gürültüler ise termal ve diğer gürültülerdir. Tanımlanan iki gürültü çeşidini gidermek için literatürde birçok algoritma önerilmektedir (Ahmed, Yamany, Mohamed, Farag, \& Moriarty, 2002; Gudbjartsson \& Patz, 1995; Manjón et al., 2008; Manjón, Coupé, Buades, Collins, \& Robles, 2012; Tustison et al., 2010; Van Leemput, Maes, Vandermeulen, \& Suetens, 1999). Bias ve diğer gürültü tiplerini gidermek için literatürde tanımlanan adaptif algoritmalar SPM8 ve VBM8 kütüphanelerine gömülmüştür. Bias giderme için ayrık kosinüs dönüşümünün temel fonksiyonları kullanılmaktadır (Ridgway, 2008). Rassal gürültüler için ise markov rastgele alanları ve uzaysal adaptif yerel olmayan filtreler kullanılmaktadır (F Kurth et al., 2010; Manjón, Coupé, Martí-Bonmatí, Collins, \& Robles, 2010; Rajapakse, Giedd, \& Rapoport, 1997). Şekil 2.5a'da bias ve diğer rassal gürültülerin olduğu 3B MR görüntüsü, Şekil 2.5' de görüntüye binen diğer ve bias gürültüler, Şekil 2.5c'de gürültüden arındırılmış 3B görüntü verilmiştir. Şekil 2.5 b'de verilen görüntü gürültülü ve gürültüden arındırılmış görüntünün birbirinden 3B uzayda çıkarılması ile elde edilmiştir. 


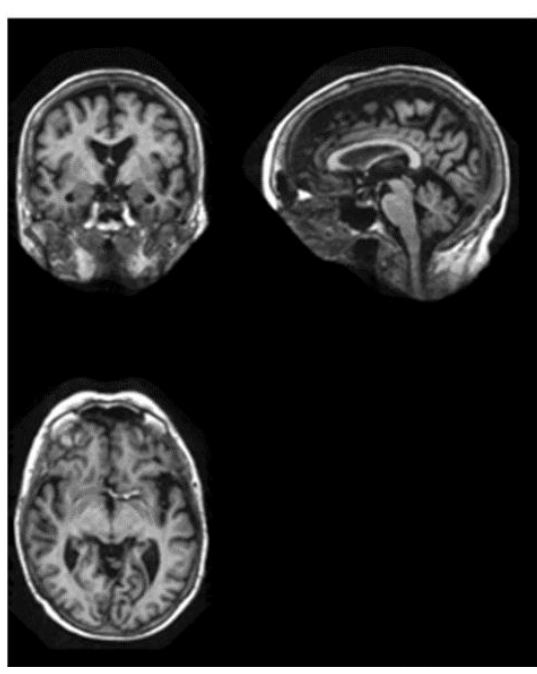

(a)

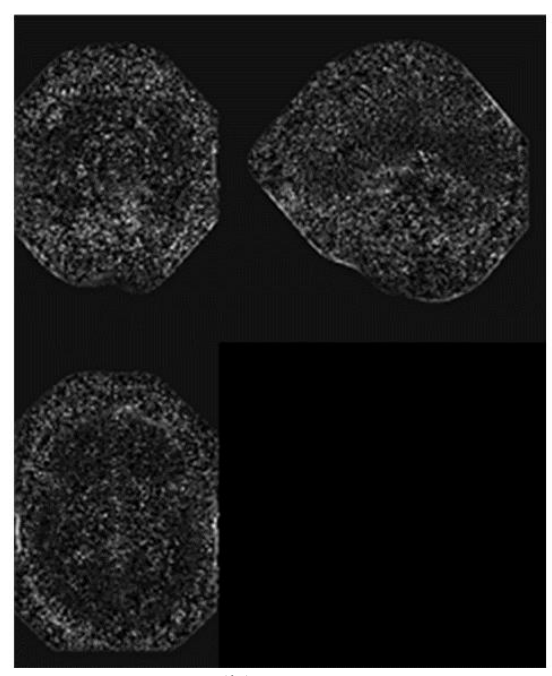

(b)

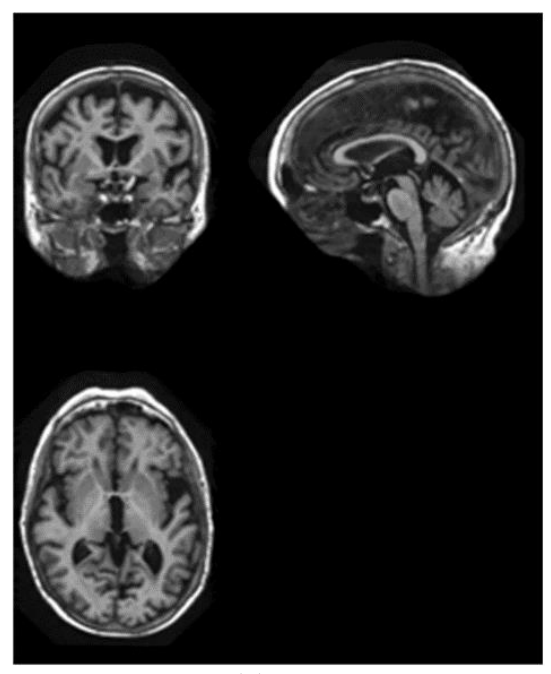

(c)

Şekil 2.5. (a) Bias ve rassal gürültülü görüntü (b) Görüntüden çekilen bias ve rassal gürültü (c) Bias ve rassal gürültülerden arındırılmış görüntü

\subsection{Normalizasyon}

3B MR görüntülerinin grup içi ve gruplar arası karşılaştırma çalışmalarında her insanın kafa büyüklüğünün farklı olması analizi çıkmaza sokmaktadır. Bundan dolayı görüntüleri aynı koordinat düzlemine oturtulması için normalizasyon işlemi geliştirilmiştir. Normalizasyon belli kurallar çerçevesinde görüntü voksellerini tanımlanan uzaya tekrar örneklemektedir. Görüntüler aynı koordinat sisteminde ve aynı boyutlarda olduğu için güçlü analizler yapılabilmektedir. Böylece grup içi ve gruplar arası karşılaştırmalar, hacim analizleri, atrofi farklılıkları gözlemlenebilmekte, yapılan işlemin istatistiksel gücü artırılmaktadır (Şenvardar, 2011). SPM8 programı ve VBM8 eklentisi Montreal Neurological Institue (MNI) uzayını normalizasyon işleminde referans almaktadır. Bu uzay da temelde 1988 yılında Talairach ve Tourneux isimli iki bilim adamının 60 yaşındaki bir fransız kadının kadavra beyninden tanımladıkları Talairach koordinat sistemini referans almaktadır. Bu sistem beynin şekil ve büyüklüğünden bağımsız olarak hiçbir atrofiden etkilenmediğini iddia ettikleri AC noktasını beynin merkezi olarak kabul etmektedir. AC/PC noktalarından geçen çizgiyi orijin çizgisi olarak kabul etmişlerdir. Önerilen teknik sadece bir insanın kafa koordinat sistemini modellemesine rağmen uzun süre sayısal işlemlerde standart olarak kullanılmıştır. Bu sistemi kullanan bilgisayar destekli sayısal analizlerde beyin tekrar boyutlandırılırken hatalar meydana gelebilmektedir (Brett, Johnsrude, \& Owen, 2002; Dağdeviren, 2012; Lancaster \& Fox, 2000; Talairach \& Tournoux, 1988). MNI bu sistemi tüm popülasyonu temsil edebilecek şekilde tekrar revize etmiş, kendi koordinat sistemini geliştirmiştir. Aynı zamanda koordinat sistemine görüntülerin çakıştırılması için şablon görüntüler önermiştir. Önerilen koordinat sistemi iki aşamada türetilmiştir. İlk olarak 241 3B sağlıklı MR görüntüleri talairach eksenine çakıştırılarak ortalamaları alınmış ve geçiş görüntüsü elde edilmiştir. İkinci aşamada 305 sağlıklı MR görüntüsü elde edilen geçiş görüntüsüne çakıştırılarak MNI 305 şablonu elde edilmiştir. SPM programının 96 ve 99 versiyonları MNI 305 şablon görüntüsünü kullanmıştır. Güncel versiyonları 152 beyin görüntüsünün afin dönüşümü kullanarak elde ettiği ICBM 152 şablonunu kullanmaktadır (Brett, Christoff, Cusack, \& Lancaster, 2001; Dağdeviren, 2012; Evans et al., 1993; Evans, Collins, \& Milner, 1992). Şekil 2.6a'da Talairach tarafından önerilmiş olan sistem, Şekil 2.6b'de MNI tarafından önerilen koordinat sistemi verilmiştir. Normalizasyon işlemi sonunda şablona çakıştırılan MR görüntüleri aynı voksel boyutu, görüntü boyutu ve dilim sayısına eşit olmaktadır. Bu işlem sırasında beynin konsantrasyonu ya da hacim analizine göre farklı yöntemler kullanılmakta görüntü içeriğindeki bilgi değiştirilmemektedir. Literatürde normalizasyon için birçok yöntem önerilse de en güçlü algoritma John Ashburner tarafından önerilmiştir (Ashburner, 2007). Anatomical Registration Through Exponentiated Lie Algebra (DARTEL) yöntemi farklı normalizasyon algoritmaları içinde en iyi çakıştırmayı vermektedir. DARTEL yönteminin aynı zamanda farklı merkezlerden farklı görüntüleme protokolleri ile alınan görüntüler arasında en iyi çakıştırmayı verdiği belirtilmiştir (Goto et al., 2013; Klein et al., 2009). Normalizasyon işlemi bu çalışmada segmentasyon ve beyin dışı yapıların atılması işlemi içerisinde entegre bir şekilde yapılmıştır. 

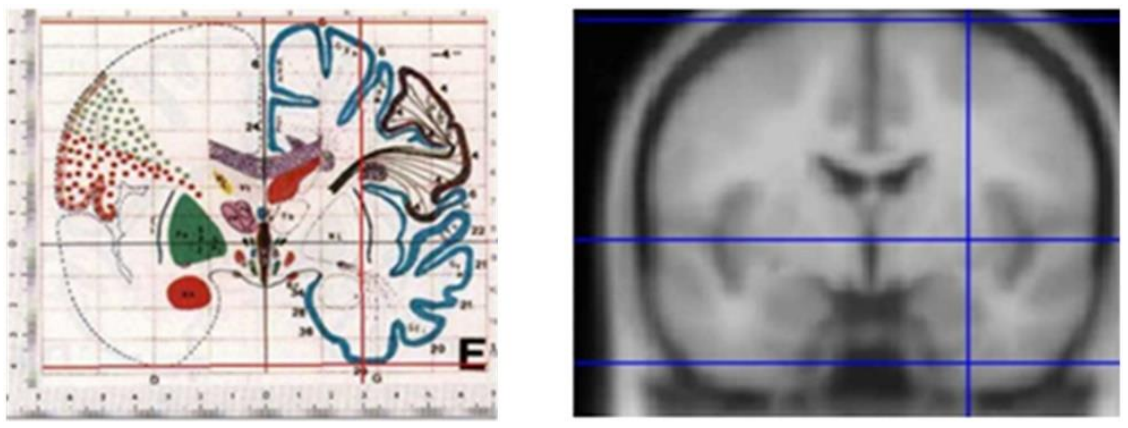

Şekil 2.6. (a) Talairach Koordinat Sistemi (b) MNI Koordinat Sistemi (Ridgway, 2010a)

\subsection{Beyin Dışı Yapıların Atılması}

3B MR görüntülerinin sayısal analizlerinde kemik, zar gibi yapılar gereksiz işlemlerin yapılmasına neden olmaktadır. Anlamlı bilgilerin bulunduğu beyin dokusuna zarar vermeden beyin dışı yapıların atılması gereklidir. Bu işlem için daha önceden oluşturulmuş öncül olasılık haritalarını kullanılmaktadır (Ridgway, 2010a). Görüntüler MNI uzayına normalize edilmiş şekilde beyin dışı yapılar giderilmektedir. Şekil 2.7'de beyin dışı yapıları atmak için kullanılan öncül olasılık haritaları verilmiştir. Şekil 2.8a'da OAS1_0028 nolu görüntünün kemikli yapısı ve 3B modeli, Şekil 2.8b'de beyin dışı yapıların atılmış olduğu görüntü ve 3B modeli verilmiştir.
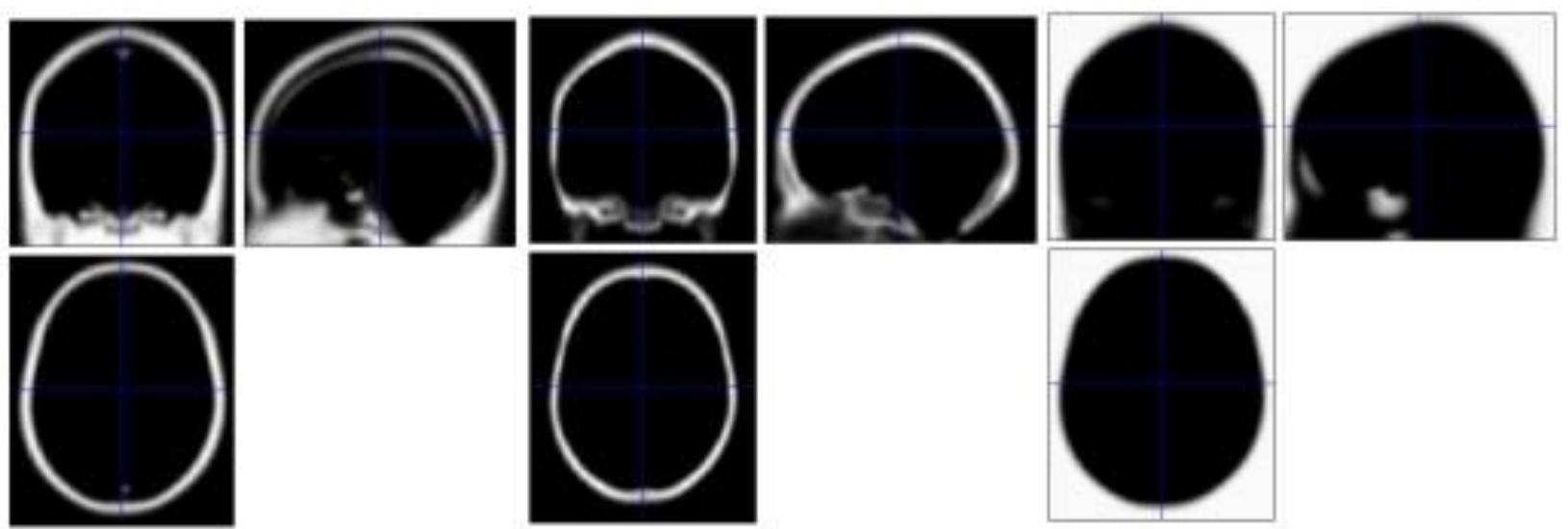

Şekil 2.7. Beyin dışı yapılar öncül olasılık haritaları(Ridgway, 2010a)
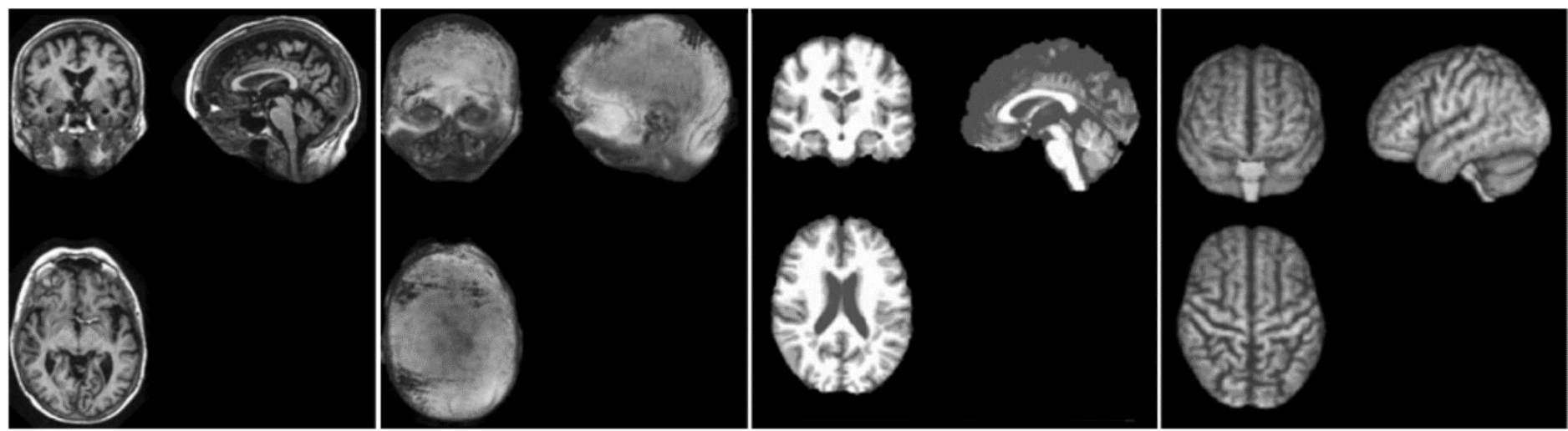

Şekil 2.8. (a) OAS1_0028 nolu görüntü ve 3B model (b) Beyin dışı yapıların normalize koordinatlarda atılmış durmu ve 3B model (Öziç, 2018) 


\subsection{Segmentasyon}

Segmentasyon işlemi beyni oluşturan Beyaz Madde (BM), Gri Madde (GM) ve Beyin Omurilik Sıvısı (BOS) bölgelerinin üç boyutlu olarak birbirinden ayrılması işlemdir. MR görüntülerinde GM gri tonda, BM beyazımsı tonda ve BOS bölgesi siyah tonda voksellerden oluşmaktadır. GM madde sinirlerin bulunduğu BM'yi kaplamakta, BOS ise bu iki bölge ve kemik dokusu arasında kalan bölgelerde sıvı halde bulunmaktadır. Bu bölgelerin 3B segmentasyonu hacim analizlerin yapılması için önemli bir aşamadır. GM ve BM 3B segmentasyonu grup içi ve gruplar arası katı karşılaştırmaların yapılabilmesi için gereklidir. Segmentasyon işlemi öncesi ve sonrası bazı ön işleme metotları kullanıldı ̆̆ için ön işleme basamakları arasına dahil edilmiştir. Bölgeler arasındaki voksel intensite geçişlerine daha yakından bakıldığında hangi vokselin hangi kümeye dahil olduğu manuel olarak kestirilememektedir. SPM programının ilk versiyonları hangi vokselin hangi kümeye dahil olduğunun belirlenmesi için gauss karışım modeli kullanmıştır. Bu model bayes teoremi ve bölgeler için türetilmiş öncül olasılık haritaları kullanmış, voksellerin ilgili bölgeye ne kadar olasılıkla dahil olduğunu belirleyerek segmentasyon işlemi yapmıştır (Ashburner \& Friston, 2000). SPM8 programında bias düzeltmesi, normalizasyon ve segmentasyon işleminin bir arada tanımlandığı birleştirilmiş segmentasyon (unified segmentation) yapılabilmektedir (Ashburner \& Friston, 2005). VBM8 kütüphanesi öncül olasılık işlemine gerek kalmadan Maxiumum A Posterior ve parçalı hacim tekniği ile segmentasyon işlemi yapmaktadır. (F Kurth et al., 2010; Rajapakse et al., 1997; Tohka, Zijdenbos, \& Evans, 2004) Normalizasyonlu segmentasyon işlemi için düşük dereceli uzaysal normalizasyon veya yüksek dereceli DARTEL normalizasyon işlemi seçilebilmektedir. Seçilen işleme göre kullanılan normalizasyon şablonları değişmektedir. VBM8 kütüphanesinde gerekli parametre değerleri girildiğinde ham görüntü bias ve diğer gürültülerden giderilmiş, normalizasyon ve segmentasyon işlemi yapılmış bir şekilde elde edilebilmektedir (F Kurth et al., 2010). Şekil 2.9a'da OASIS 28 nolu ham görüntünün normalize uzayda GM ve 3B modeli, Şekil 2.9b'de BM ve 3B modeli, Şekil 2.9c'de BOS ve 3B modeli verilmiştir.

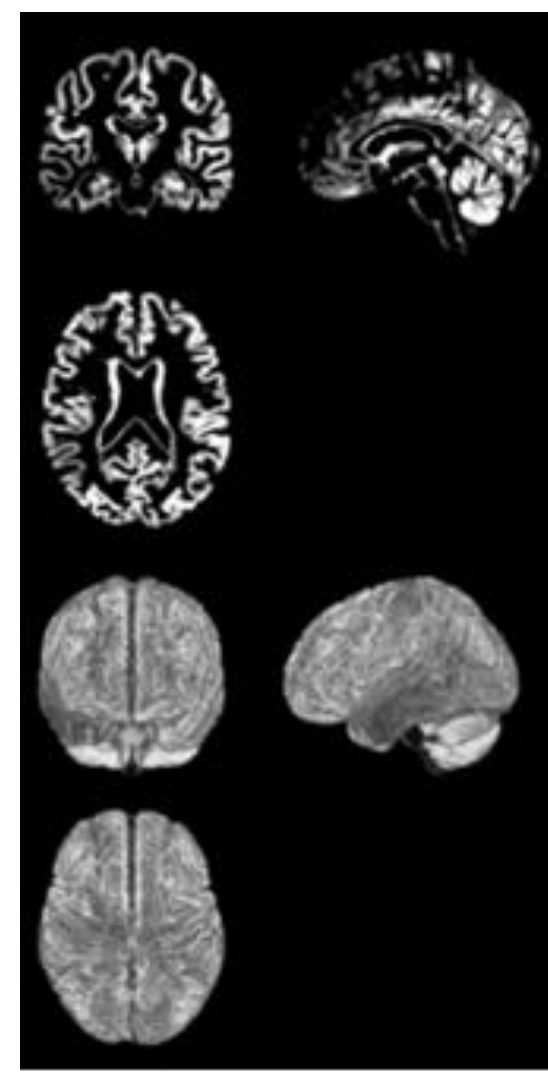

(a)

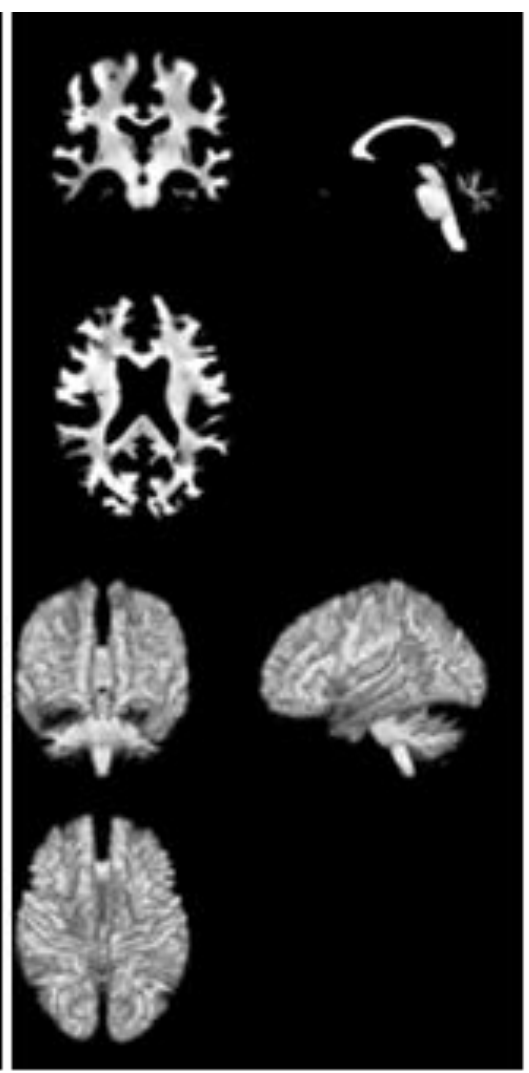

(b)

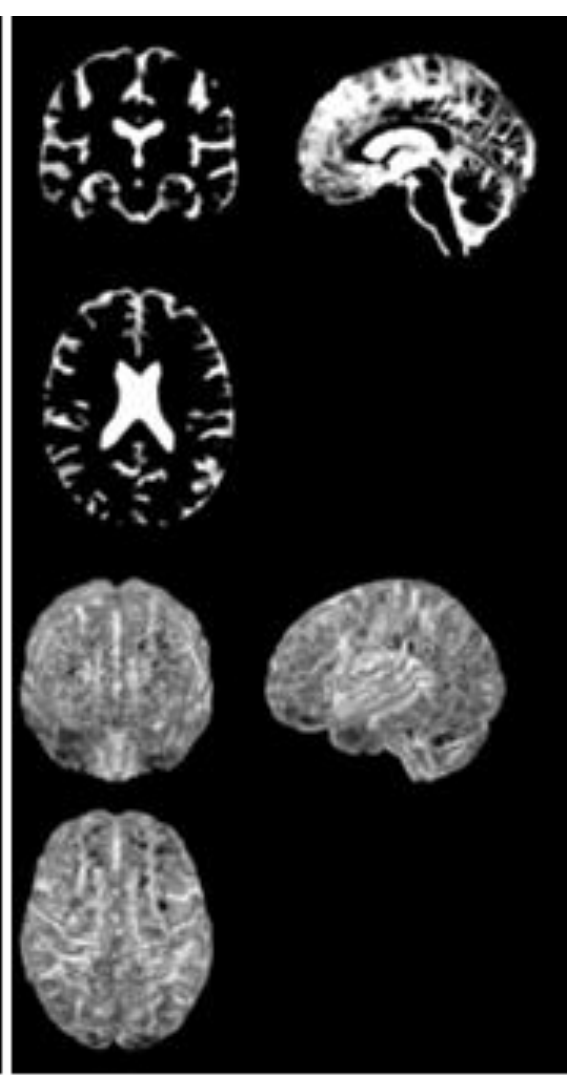

(c)

Şekil 2.9. OAS1_0028 nolu deneğin VBM8 kütüphanesi ile (a) GM segmentasyonu ve 3B modeli (b) BM segmentasyonu ve 3B modeli (c) BOS segmentasyonu ve 3B modeli (Öziç, 2018)

\subsection{Modülasyon}

Modülasyon, segmentasyon işleminden sonra native uzaydaki hacmin segmente edilen uzayda da korunması için yapılan bir ön işleme yöntemidir. Normalize uzayda segmentasyon işlemi için doku konsantrasyonun korunduğu veya hacim bilgisinin korunduğu uzay kullanıcı tarafından belirlenir. İşlem sonucu hacim analizi yapılacaksa modülasyonlu görüntüler, katı değişikliklerin incelenmesi için ise doku konsantrasyonun korunduğu görüntüler kullanılmalıdır. Modülasyon işlemi normalizasyon işlemi sırasına voksel değerlerinin jacobian determinat işleminden geçilmesi ile uzayda vokselleri tekrar örneklemektedir (Mechelli, Price, Friston, \& Ashburner, 2005). Amaca göre istenilen görüntüler VBM8 kütüphanesinde gerekli parametreler ayarlanarak elde edilebilmektedir. Modülasyonlu görüntüler nispeten daha gri renktedir. OAS1_0028 nolu deneğin Şekil 2.10a'da GM normalize modülasyonsuz 
görüntüsü, Şekil 2.10b'de GM normalize modülasyonlu görüntüsü, Şekil 2.10c'de BM normalize modülasyonsuz görüntüsü, Şekil 2.10d'de BM normalize modülasyonlu görüntüsü verilmektedir.
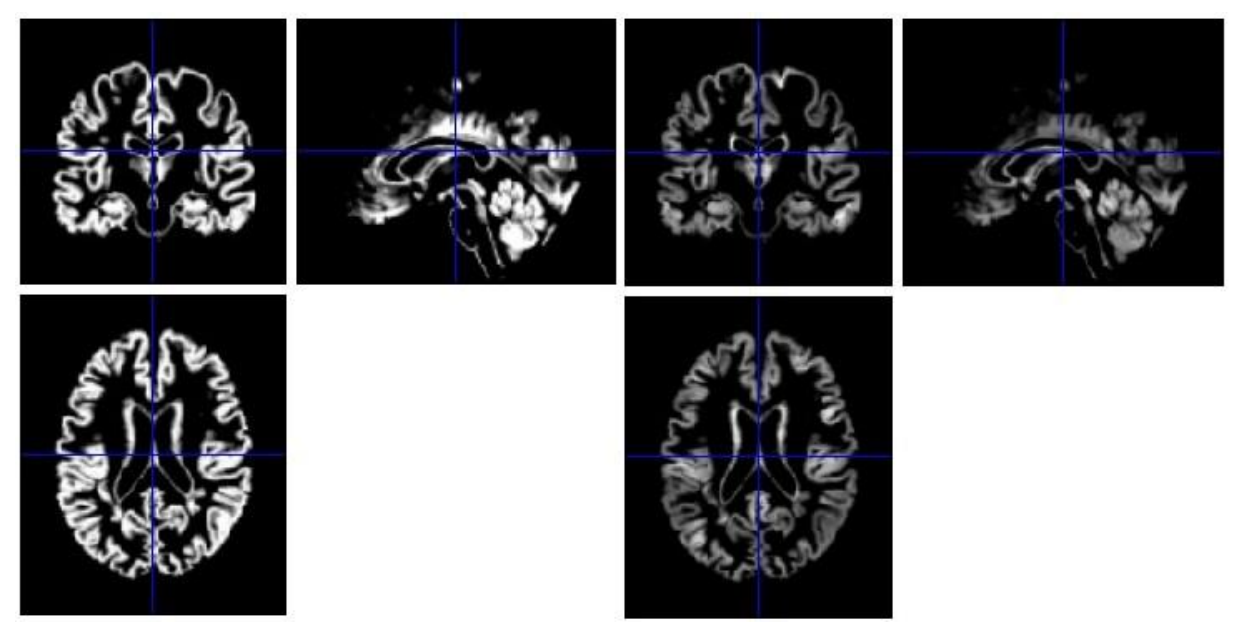

(a)

(b)
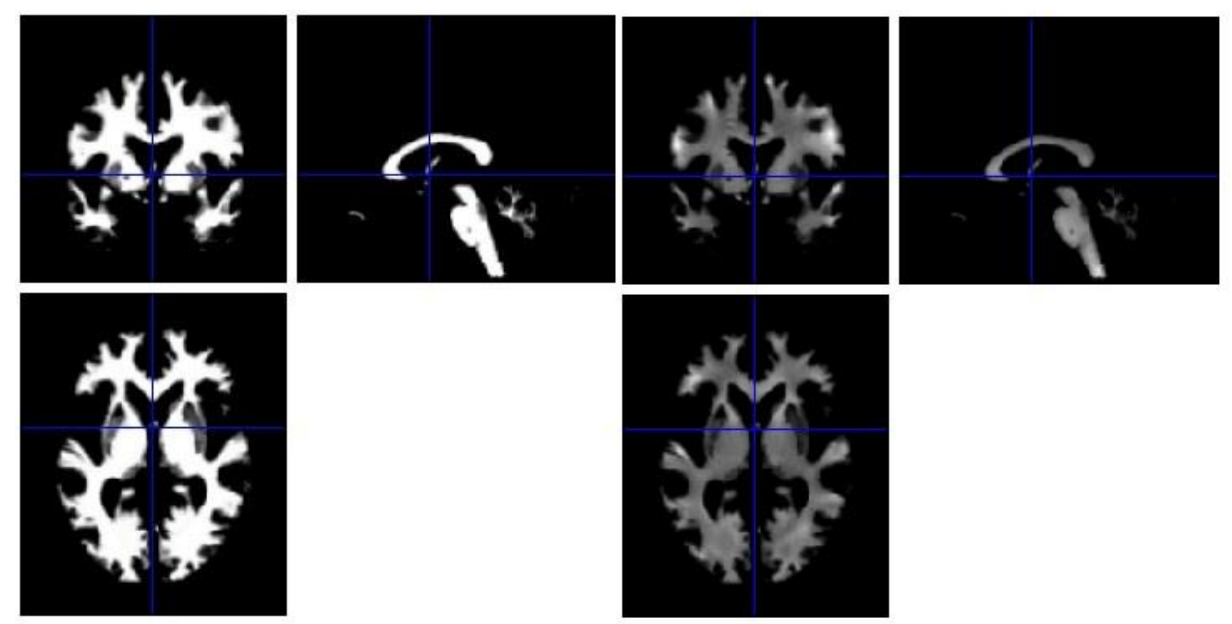

(c)

(d)

Şekil 2.10. (a) Modülasyonsuz GM (b) Modülasyonlu GM (c) Modülasyonsuz BM (d) Modülasyonlu BM (Öziç, 2018)

\subsection{Yumuşatma}

Yumuşatma işlemi segmente edilmiş modülasyonlu veya modülasyonsuz görüntülerin 3B bir gauss filtre ile yumuşatılmasıdır. Filtre ile görüntü konvolüsyon işlemine tabi tutulur. Yumuşatma 3B yapısal MR ve fonksiyonel MR görüntü gruplarının kendi içlerinde karşılaştırılmasında istatistiksel gücü artıran önemli bir parametredir. Gauss filtrenin en önemli değişkeni Full Width at Half Maximum (FWHM) büyüklüğ̈üür (Ashburner et al., 2008; Şenvardar, 2011). SPM8 programında varsayılan değer 8x8x8 mm büyüklüğündedir. Bu değerin artması ve azalması ile görüntüdeki yumuşatma değişmektedir. Yapısal MR görüntülerinin voksel tabanlı morfometri analinden önce yumuşatma işlemi rutin olarak yapılmaktadır (Ridgway, 2008). Şekil 2.11a ve Şekil 2.11b'de modülasyonlu segmente normalize edilmiş GM, Şekil 2.11c ve Şekil 2.11d'de modülasyonlu segmente normalize edilmiş BM görüntülerin 8x8x8 FWHM ile yumuşatma işleminden geçirilmiş şekilleri verilmiştir. 

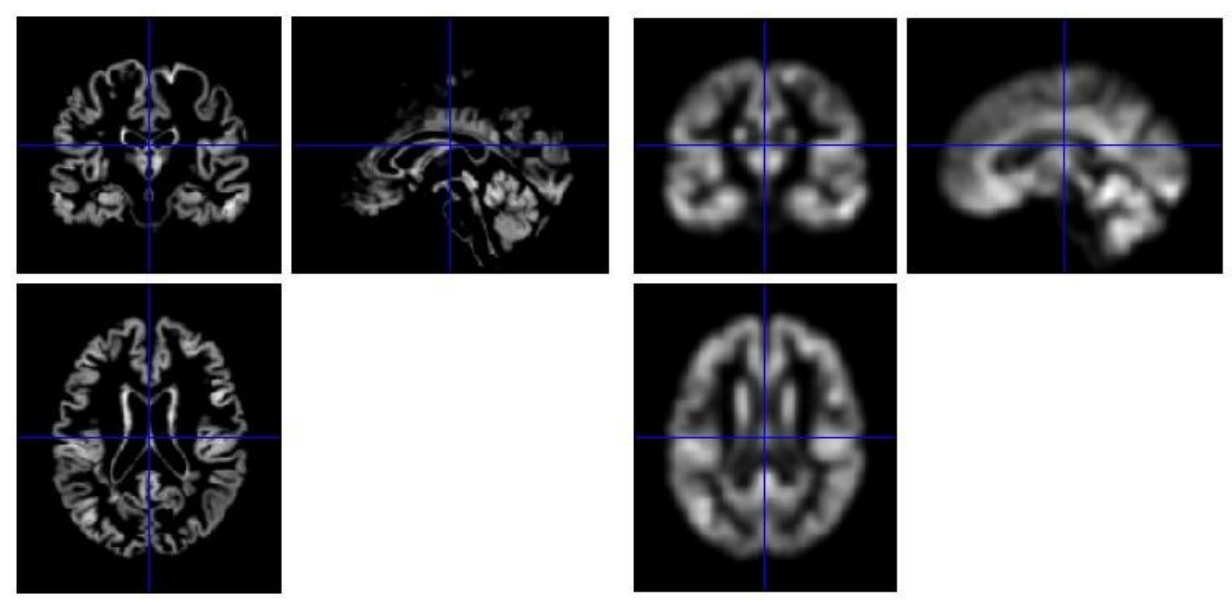

(a)
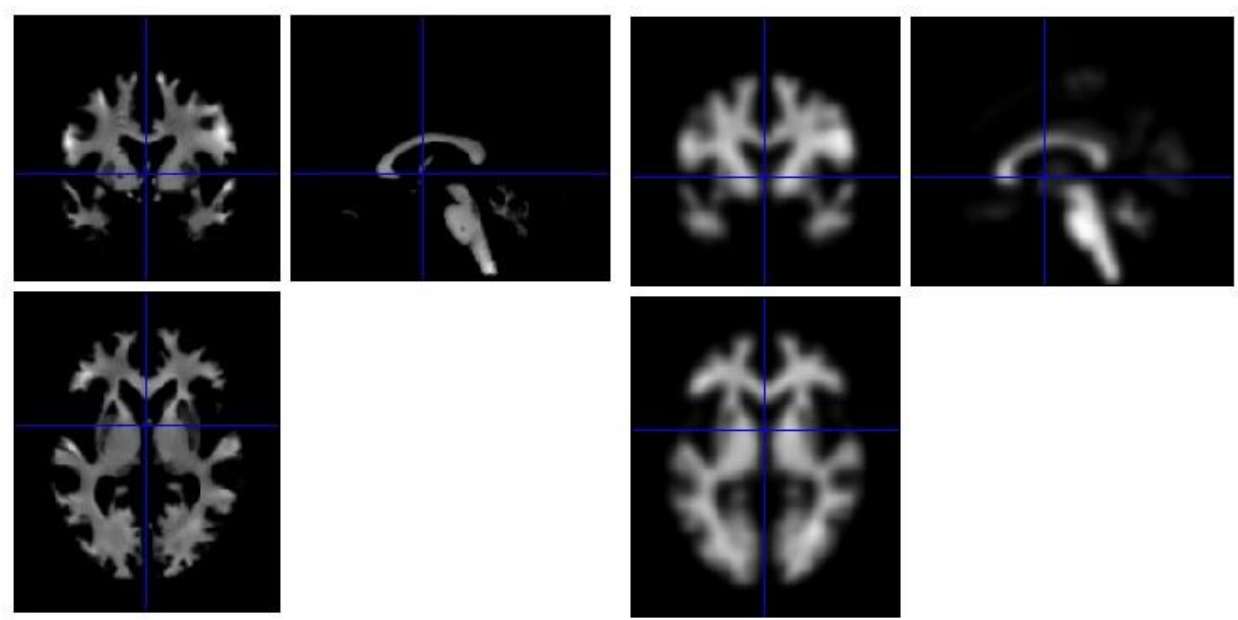

(b)

(c)

(d)

\begin{abstract}
Şekil 2.11. (a) Modülasyonlu GM (b) FWHM ile yumuşatılmış modülasyonlu GM (c) Modülasyonlu BM (d) FWHM ile
\end{abstract} yumuşatılmış modülasyonlu BM (Öziç, 2018)

\title{
2.11. Birlikte Çakıştırma
}

Birlikte çakıştırma (coregister) iki farklı görüntü boyutlu ve voksel boyutlu 3B görüntülerin interpolasyon işleminden geçirilerek aynı boyutlara hizalanması işlemidir. SPM8 programında "Coregister Reslice” aracı ile kaynak ve referans görüntüler girilerek işlem gerçekleştirilir. En önemli parametre interpolasyon işleminin belirlenmesidir. İnterpolasyon ile tekrar dilimleme esnasında voksel komşuluklarında nasıl bir örnekleme metodu izleneceği belirlenir. Program varsayılan olarak trilinear seçeneğini sunmaktadır. Ancak en yakın komşu (nearest neighbour) ve 2-7. dereceden BSpline interpolasyon yöntemleri kullanıcın isteğine göre seçilebilmektedir (Ashburner et al., 2008). Şekil 2.12.'de Automated Anatomical Labeling (AAL) atlas ile MNI uzayına normalize edilmiş görüntünün birlikte çakıştırma işleminden sonra üst üste oturtulması gösterilmiştir. Böyle bir işlemin yapılabilmesi için her iki görüntünün de merkez noktasının aynı olması ve MNI uzayına normalize edilmiş olması gerekmektedir. 


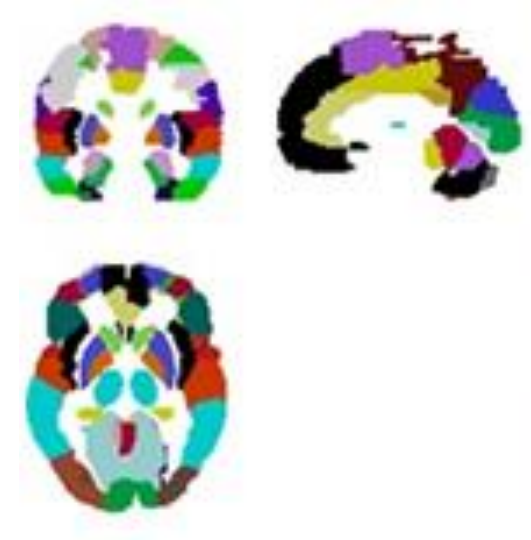

(a)

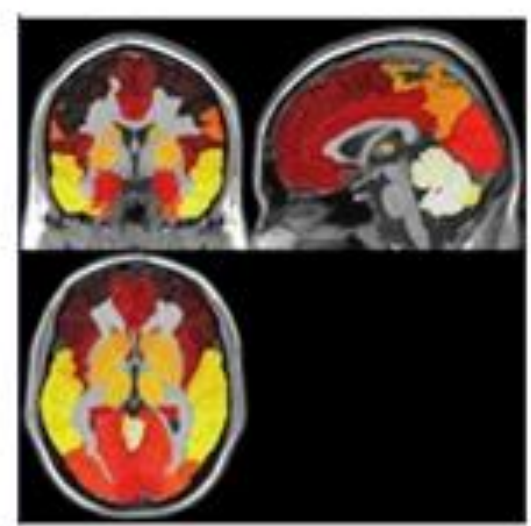

(b)

Şekil 2.12. (a) AAL atlas (b)Normalize edilmiş yapısal MR görüntüsüne çakıştırılması (Öziç, 2018)

\section{Araştırma Sonuçları ve Tartışma}

MR görüntüleri medikal görüntüler içerisinde analizi son derece zor olan görüntülerdir. Beyindeki bölgelerin voksel intesite geçiş sınırlarının manuel olarak net bir şekilde çizilememesi ve keskin sınırların belirlenememesi ilgili bölgelerin ölçümlerini zorlaştırmaktadır. Aynı zamanda manuel analizlerin kişiden kişiye değişebilmesi ve bu analizlerin kullanıcı bağımlı olması sonuçları göreceli yapmaktadır. Analizlerde bir diğer problem ise süredir. Hasta sayısının fazla olması ve radyolog sayısının sınırlı olması analizin süre faktörünü etkilemektedir. Bir kesit üzerinde yapılacak bir ölçümün diğer kesitler üzerinde benzer şekilde yapılması çok fazla süre kaybına yola açacaktır. Bu problemlerin üstesinde gelmek için literatürde tanımlanan bilgisayar destekli sayısal araçlar bir alternatif olarak kullanılabilir. Bu çalışmada, 3B MR görüntü analizlerinde kullanılabilecek farklı sayısal ön işleme yöntemleri detaylı bir şekilde incelenmiştir. SPM8, MRIcro programları ve VBM8 kütüphanesi kullanılarak yöntemlerin hangi sıralamada ve nasıl kullanılacağı araştırılmış̦ır. Herhangi bir analizde ön işleme yöntemlerinin hepsinin kullanılmasına gerek yoktur. Hacim analizi için modülasyonlu görüntülerin elde edilmesi yeterli iken (Öziç \& Özşen, 2020), voksel tabanlı morfometri gibi grup analizlerinin yapılacağı işlemlerde yumuşatılmış görüntüler elde edilmelidir. Tümör, multipl skleroz ve inme gibi lezyonların analizi görüntü işleme teknikleri ile yapılacaksa arka plandaki gereksiz detayları azaltmak için beyin dışı yapıların atılması yeterli olacaktır. Dolayısıyla ön işleme yöntemleri gerçekleştirilecek çalışmanın amacına dönük olarak belli bir düzen içinde yapılmalıdır. Bir adımda yapılacak olan herhangi bir hata diğer adımlarda problem olarak ortaya çıkmaktadır. Parametre girişlerindeki hatalarda veya bir adımın atlanmasında, işlem düzeni ya ilerlememekte ya da elde edilen görüntüler bozulmaktadır. Bundan dolayı kullanıcı parametre girişlerini dikkatli seçmeli ve istenilen çıktı için adımlarını dikkatli bir şekilde yapmalıdır. Çalışmada ortaya çıkan bir diğer sonuç istenilen adımların hızlı bir şekilde yapılabilmesidir. GM gibi bölgelerin tüm kesitlerde manuel bir şekilde segmentasyonu saatler alabilecek iken, program ile hızlı bir şekilde türetilebilmektedir. Programlar içerisinde güçlü algoritma ve modellerin kullanılması çıktıların hızlı bir şekilde elde edilmesini sağlamaktadır. Ülkemizde konu ile ilgili çok fazla çalışma olmadığından bu çalışmada belirtilen yöntem ve basamaklar araştırmacılar için faydalı bir kaynak olacak niteliktedir.

\section{Sonuç}

Medikal görüntülerin sayısal analizi için görüntülerin ön işleme süreçlerinden geçirilmesi önemli bir basamaktır. Kullanılan görüntü deneklerinin kafa büyüklüklerinin farklı olması, gürülttüler, beyin dışı yapılar, standardizasyon problemleri grup içi, gruplar arası ve boylamsal veri analizlerini son derece zorlaştırmaktadır. Bu çalışmada 3B T1 ağırlıklı yapısal MR görüntüleri için ön işleme yöntemleri tanımlanmış ve bir görüntü üzerinde uygulamaları yapılmıştır. Çalışmada tanımlanan ön işleme yöntemleri kullanılarak grup içi ve gruplar arası atrofi ve hacim farklılıkları voksel tabanlı morfometri yöntemi ile incelenebilir. Modülasyonlu görüntüler üzerinden global ve lokal bölge hacimleri hesaplanabilir. Ön işleme yöntemlerinde yapılan bir eksiklik veya düzensizlik sonraki adımlarda kullanıcıya hata yaptırabilir. Bundan dolayı gerekli ön işleme araçları hedefe dönük belli bir düzen içerisinde kullanılmalı ve hedef çalışmaya dönük olmalıdır. Ön işleme yöntemlerinin sadece yapısal MR'da değil, fonksiyonel MR, difüzyon tensör görüntüleme ve pozitron emisyon tomografi görüntülerinde de benzer kullanımları vardır. Gelecek çalışmalarda diğer görüntüleme tekniklerinin ön işleme yöntemleri ile beraber sayısal analizleri incelenecektir. Ayrıca Linux tabanlı FSL ve Freesurfer programlarında kullanılan ön işleme ve analiz yöntemleri ile beraber SPM8 programındaki yöntemlerin performans karşılaştırmaları yapılacaktır. MR cihazlarından görüntü çekildikten sonra ön işleme ve analizlerin güçlü bilgisayarlar ile hızlı bir şekilde yapılması ve doktorlar önüne analizlerin bir ön bilgi olarak gelmesi gelecekte tıp alanında beklenen bir teknolojidir. 


\section{Kaynakça}

Ahmed, M. N., Yamany, S. M., Mohamed, N., Farag, A. A., \& Moriarty, T. (2002). A modified fuzzy c-means algorithm for bias field estimation and segmentation of MRI data. IEEE transactions on medical imaging, 21(3), 193-199.

Ashburner, J. (2007). A fast diffeomorphic image registration algorithm. Neuroimage, 38(1), 95-113.

Ashburner, J., Barnes, G., Chen, C., Daunizeau, J., Flandin, G., Friston, K., . . Litvak, V. (2008). SPM8 manual. Functional Imaging Laboratory, Institute of Neurology, 41.

Ashburner, J., \& Friston, K. J. (2000). Voxel-based morphometry-the methods. Neuroimage, 11(6), 805-821.

Ashburner, J., \& Friston, K. J. (2005). Unified segmentation. Neuroimage, 26(3), 839-851.

Brett, M., Christoff, K., Cusack, R., \& Lancaster, J. J. N. (2001). Using the Talairach atlas with the MNI template. 13(6), 85-85.

Brett, M., Johnsrude, I. S., \& Owen, A. M. (2002). OPINION: The problem of functional localization in the human brain. Nature reviews. Neuroscience, 3(3), 243.

Dağdeviren, Z. A. (2012). Hastaların Yapısal MR Görüntülerinin MNI görüntü Uzayına Kayıtlanması. (Yüksek Lisans Tezi), Ege Üniversitesi Fen Bilimleri Enstitüsü, İzmir.

Davis, E., \& Loh, E. (2011). Methods for Dummies: Coregistration and Spatial Normalization. Retrieved from http://www.fil.ion.ucl.ac.uk/mfd_archive/2011/page1/mfd2011_coregistration.pptx

Evans, A. C., Collins, D. L., Mills, S., Brown, E., Kelly, R., \& Peters, T. M. (1993). 3D statistical neuroanatomical models from 305 MRI volumes. Paper presented at the Nuclear Science Symposium and Medical Imaging Conference, 1993., 1993 IEEE Conference Record.

Evans, A. C., Collins, D. L., \& Milner, B. (1992). An MRI-based stereotactic atlas from 250 young normal subjects. Paper presented at the Soc. neurosci. abstr.

Fischl, B. (2012). FreeSurfer. Neuroimage, 62(2), 774-781.

Goto, M., Abe, O., Aoki, S., Hayashi, N., Miyati, T., Takao, H., . . Mori, H. (2013). Diffeomorphic Anatomical Registration Through Exponentiated Lie Algebra provides reduced effect of scanner for cortex volumetry with atlas-based method in healthy subjects. Neuroradiology, 55(7), 869-875.

Gudbjartsson, H., \& Patz, S. (1995). The Rician distribution of noisy MRI data. Magnetic resonance in medicine, $34(6), 910-914$.

Gülay, E., \& İçer, S. (2020). Evaluation of Lung Size in Patients with Pneumonia and Healthy Individuals. Avrupa Bilim ve Teknoloji Dergisi, (Özel Say1), 304-309.

Hemanth, D. J., \& Anitha, J. (2012). Image Pre-processing and Feature Extraction Techniques for Magnetic Resonance Brain Image Analysis. In Computer Applications for Communication, Networking, and Digital Contents (pp. 349-356): Springer.

Jenkinson, M., Beckmann, C. F., Behrens, T. E., Woolrich, M. W., \& Smith, S. M. (2012). Fsl. Neuroimage, 62(2), $782-790$.

Klein, A., Andersson, J., Ardekani, B. A., Ashburner, J., Avants, B., Chiang, M.-C., . . Hellier, P. (2009). Evaluation of 14 nonlinear deformation algorithms applied to human brain MRI registration. Neuroimage, 46(3), 786-802.

Kurth, F., Gaser, C., \& Luders, E. (2015). A 12-step user guide for analyzing voxel-wise gray matter asymmetries in statistical parametric mapping (SPM). Nature Protocols, 10(2), 293-304.

Kurth, F., Luders, E., \& Gaser, C. (2010). VBM8 toolbox manual. Jena: University of Jena.

Lancaster, J. L., \& Fox, P. T. (2000). Talairach space as a tool for intersubject standardization in the brain. Paper presented at the Handbook of medical imaging.

Liu, Y., Collins, R. T., \& Rothfus, W. E. (2001). Robust midsagittal plane extraction from normal and pathological 3-D neuroradiology images. IEEE transactions on medical imaging, 20(3), 175-192.

Manjón, J. V., Carbonell-Caballero, J., Lull, J. J., García-Martí, G., Martí-Bonmatí, L., \& Robles, M. (2008). MRI denoising using non-local means. Medical image analysis, 12(4), 514-523.

Manjón, J. V., Coupé, P., Buades, A., Collins, D. L., \& Robles, M. (2012). New methods for MRI denoising based on sparseness and self-similarity. Medical image analysis, 16(1), 18-27.

Manjón, J. V., Coupé, P., Martí-Bonmatí, L., Collins, D. L., \& Robles, M. (2010). Adaptive non-local means denoising of MR images with spatially varying noise levels. Journal of Magnetic Resonance Imaging, 31(1), 192-203.

Marcus, D. S., Wang, T. H., Parker, J., Csernansky, J. G., Morris, J. C., \& Buckner, R. L. (2007). Open Access Series of Imaging Studies (OASIS): cross-sectional MRI data in young, middle aged, nondemented, and demented older adults. Journal of cognitive neuroscience, 19(9), 1498-1507.

Mechelli, A., Price, C. J., Friston, K. J., \& Ashburner, J. (2005). Voxel-based morphometry of the human brain: methods and applications. Current medical imaging reviews, 1(2), 105-113.

Özel, P. (2020). A Decision Support System to Assess the Masses in Breast Tissue using Classification Algorithms. Avrupa Bilim ve Teknoloji Dergisi, (Özel Sayı), 114-119.

Öziç, M. Ü. (2018). 3B Alzheimer MR Görüntülerinin Sınıflandırılmasında Yeni Yaklaşımlar. (Doktora Tezi), Selçuk Üniversitesi, Fen Bilimleri Enstitüsü.

Öziç, M. Ü., \& Özşen, S. (2020). Comparison Global Brain Volume Ratios on Alzheimer's Disease Using 3D T1 Weighted MR Images. Avrupa Bilim ve Teknoloji Dergisi, (18), 599-606.

Patil, S., \& Udupi, V. (2012). Preprocessing to be considered for MR and CT images containing tumors. IOSR journal of electrical and electronics engineering, 1(4), 54-57.

Rajapakse, J. C., Giedd, J. N., \& Rapoport, J. L. (1997). Statistical approach to segmentation of single-channel cerebral MR images. IEEE transactions on medical imaging, 16(2), 176-186.

Ridgway, G. (2008). Voxel-Based Morphometry with Unified Segmentation Retrieved from http://www.fil.ion.ucl.ac.uk/spm/course/slides08-zurich/Ged_seg_vbm.ppt 
Ridgway, G. (2010a). Spatial Preprocessing. Retrieved from http://www.fil.ion.ucl.ac.uk/spm/course/slides10vancouver/01_Spatial_Preprocessing.pdf

Ridgway, G. (2010b). SPM Course: Voxel Based Morphometry Practical Retrieved from http://www0.cs.ucl.ac.uk/staff/g.ridgway/zurich/vbm_practical_zurich2010.ppt

Rorden, C. (2005). MRIcro. Retrieved from https://people.cas.sc.edu/rorden/mricro/mricro.html

Şenvardar, E. K. (2011). Nörogörüntülemede SPM Uygulamaları: İşlevsel MR İmgelerinde Uzaysal Önişleme. Retrieved from http://www.bad.org.tr/usk10/spmonesin.pdf

Talairach, J., \& Tournoux, P. (1988). Co-planar stereotaxic atlas of the human brain. 3-Dimensional proportional system: an approach to cerebral imaging.

Tohka, J., Zijdenbos, A., \& Evans, A. (2004). Fast and robust parameter estimation for statistical partial volume models in brain MRI. Neuroimage, 23(1), 84-97.

Tustison, N. J., Avants, B. B., Cook, P. A., Zheng, Y., Egan, A., Yushkevich, P. A., \& Gee, J. C. (2010). N4ITK: improved N3 bias correction. IEEE transactions on medical imaging, 29(6), 1310-1320.

UCL. (2020). SPM8. Retrieved from https://www.fil.ion.ucl.ac.uk/spm/software/spm8/

Van Leemput, K., Maes, F., Vandermeulen, D., \& Suetens, P. (1999). Automated model-based bias field correction of MR images of the brain. IEEE transactions on medical imaging, 18(10), 885-896.

Varol, A. B., \& İșeri, İ. (2019). Lenf Kanserine İliş̧kin Patoloji Görüntülerinin Makine Öğrenimi Yöntemleri ile Sınıflandırılması. Avrupa Bilim ve Teknoloji Dergisi, (Özel Sayı), 404-410. 